Provided for non-commercial research and education use. Not for reproduction, distribution or commercial use.

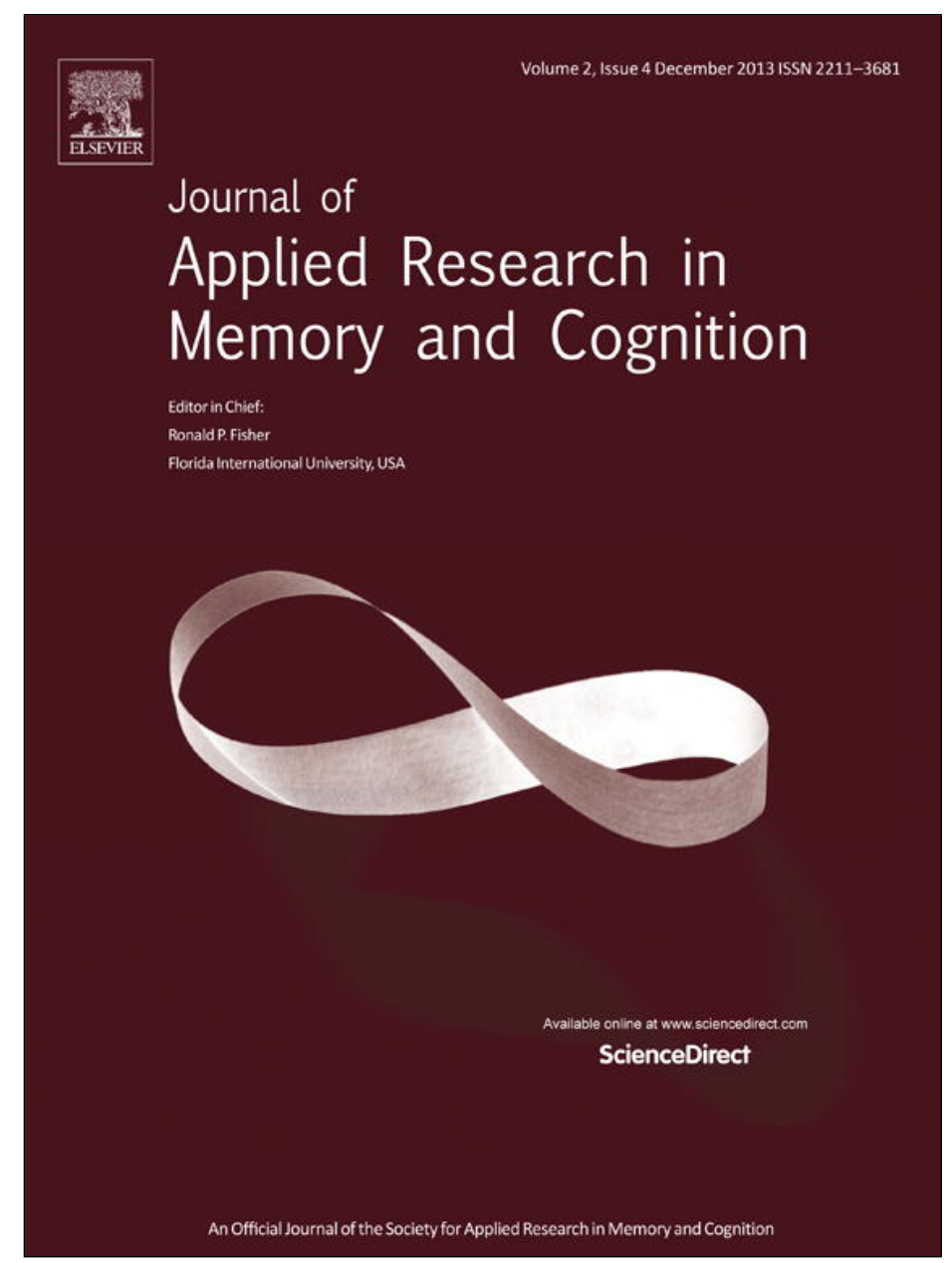

This article appeared in a journal published by Elsevier. The attached copy is furnished to the author for internal non-commercial research and education use, including for instruction at the authors institution and sharing with colleagues.

Other uses, including reproduction and distribution, or selling or licensing copies, or posting to personal, institutional or third party websites are prohibited.

In most cases authors are permitted to post their version of the article (e.g. in Word or Tex form) to their personal website or institutional repository. Authors requiring further information regarding Elsevier's archiving and manuscript policies are encouraged to visit:

http://www.elsevier.com/authorsrights 


\title{
The temporal orientation of memory: It's time for a change of direction
}

\author{
Stanley B. Klein* \\ Department of Psychological and Brain Sciences, University of California, Santa Barbara, United States
}

\section{A R T I C L E I N F O}

\section{Article history:}

Received 1 July 2013

Received in revised form 26 August 2013

Accepted 30 August 2013

Available online 8 September 2013

\section{Keywords:}

Memory

Time

Evolution

Subjective temporality

\begin{abstract}
A B S T R A C T
Common wisdom, philosophical analysis and psychological research share the view that memory is subjectively positioned toward the past: specifically, memory enables one to become re-acquainted with the objects and events of his or her past. In this paper I call this assumption into question. As I hope to show, memory has been designed by natural selection not to relive the past, but rather to anticipate and plan for future contingencies - a decidedly future-oriented mode of subjective temporality. This is not to say memory makes no reference to the past. But, I argue, past-oriented subjectivity is a by-product of a system designed by natural selection to help us face and respond to the "now and the next". I discuss the implications of the proposed temporal realignment for research agendas as well as the potential limitations of measures designed to explore memory by focusing on its retentive capabilities.
\end{abstract}

(C) 2013 Society for Applied Research in Memory and Cognition. Published by Elsevier Inc. All rights

reserved.
"What we observe is not nature itself but nature exposed to our method of questioning" (Heisenberg, 1958/1999, p. 58)

"Asking the right question is frequently more than halfway to the solution of the problem" (Heisenberg, 1958/1999, p. 35)

Add to these quotes the truism "one has a better chance of finding what he or she seeks if one knows what it is he or she is looking for" and we have a concise statement of the basic considerations of scientific inquiry - as well as potential pitfalls. An answer to the question "what is it?" determines the questions we can ask about $i t$, which in turn determines the answers nature divulges when it "pushes back". The trouble is that once we determine what it is we are looking for, simply asking questions of nature is not sufficient; the questions must be the "right" questions. And therein lays a problem: If the questions posed are not the "right" ones, the answers received will lack the resolution necessary to fine-tune our understanding of the object of inquiry.

Prior to addressing my thesis - i.e., that contrary to the belief of many lay persons and professional researchers, memory typically is not about the past; rather, its subjective temporal orientation is, and must, of adaptive necessity, be oriented toward the future (what I call the "now and the next") - I first discuss the psychological, historical and philosophical scaffolding that forms the basis for my

\footnotetext{
* Correspondence to: Department of Psychological and Brain Sciences, 551 Ucen Road, University of California, Santa Barbara, CA 93106, United States. Tel.: +1-805-893-8796.

E-mail address: klein@psych.ucsb.edu
}

treatment of memory's temporal orientation. I firmly believe that theoretical propositions, absent strong conceptual and historical grounding, run the serious risk of appearing as little more than stipulation. The reader impatient with such analysis can skip to Section 3. However, I think this would be a mistake. The approach I have adopted is something I believe we need more in psychology; too often we have a tendency to rely on terminology in place of carefully specified, conceptually grounded analyses of constructs of interest.

To head off potential confusion with my use of phrase "now and the next" (see above), I need to make clear that despite the use of the word "now" in my phrase the "now and the next" the "now" is decidedly future-oriented. Analysis of the formal properties of "present of objective time" reveals it to be instantaneous (e.g., Faye, 1989; McLure, 2005), becoming the next "present" essentially as soon as it makes an appearance (e.g., Husserl, 1964; James, 1890). It thus is a mistake to speak of the present in any way that implies measurable duration (e.g., Loizou, 1986; McLure, 2005): The present is a process consisting in an endless series "nows" instantaneously transitioning to the "next" (as well as retreating into the past; e.g., Husserl, 1964; Loizou, 1986). What is subjectively present necessarily is oriented toward, and phenomenologically indistinguishable from (i.e., instantaneous moments lack experiental resolution), what will be present - i.e., the future. Even the well-worn idea of a "specious present" (e.g., James, 1890; Kelly, 1882 ) requires inclusion of protention - i.e., orientation toward the "next" - as an essential aspect of the present. In short, the moment of the present is, formally speaking, instantaneous, an abstract point in a temporal continuum moving toward the "next" and away from the past. 


\section{Goals of paper}

In this paper, "the it of inquiry" is memory. In Section 2 I address the question "what is it that we call memory?" My goal is to craft a definition sufficiently inclusive to accommodate most of the phenomena that figure in modern taxonomies - including phenomena that historically have been seen as related to, but not part of memory proper. To put it slightly differently, my intention is to cast a net broad enough to capture most (hopefully all) of the various mental states and their behavioral correlates recognized as memory by modern "systems" approaches (for reviews see Foster \& Jelicic, 1999; Schacter \& Tulving, 1994; Tulving, 1985; Willingham \& Goedert, 2001).

In the following Section I deal with the problem of deciding the "right" questions to pose to nature. Granting memory is a property of organic matter, ${ }^{1}$ the principles of natural selection are uniquely positioned to serve as criteria for determining whether questions addressed to nature are the "right" sort. Adoption of evolutionary criteria has an additional, salutary consequence of supplementing questions that probe memory's capabilities (which have been the focus of most modern research; for discussion, see Klein, 2007; Klein, Cosmides, Tooby, \& Chance, 2002) with questions concerned with its evolved function. When interrogated with respect to function, the answers nature provides can be quite unexpected.

The question I address is one of central importance - the relation between memory and subjective temporality. To anticipate the results of my investigation (presented in Section 5), when nature is questioned with regard to memory's functional significance, the mode of temporality with which it typically is assumed to be associated (the past) is called into question: in contrast to the assumption of many philosophers and most psychologists, memory (in almost all of its presentations) is not about the past. It is about the future. From an evolutionary perspective, memory's function is to enable its owner to face life as it comes, rather than to look back as it recedes.

To put memory in its proper temporal orientation requires an appreciation of the crucial difference between what it was designed to do (its adaptive function) and the machinery by which those functions are accomplished (its biological instantiation). Though obviously related, these are not the same (see Section 5). The conceptual distinction between a system's function and the material basis by which that function is realized is brought into sharp relief by the perspective afforded by evolutionary analysis.

\section{What is memory?}

So what is memory? For the layperson, it often is taken to be the act of remembering one's past (what we now would call the episodic component of memory). Similar sentiments are found in the work of philosophers, dating to antiquity (for review, see Danziger, 2008; Draaisma, 2000; Herrmann \& Chaffin, 1988; Yates, 1966). In the Psychological Sciences, the overwhelming majority of studies explore memory in its relation to the past - e.g., we measure retention, evaluate the veracity of recollection, explore the manner in which the past is represented in the brain, assess the amount of information stored and duration of its accessibility, etc. - with fidelity to the past serving as the essential criterion (for reviews, see Puff, 1982; Tulving \& Craik, 2000).

William James captures the relation of memory to the past with characteristic clarity and concision: "A farther condition is required

\footnotetext{
1 This "self-evident" truth has not always been self-evident. In antiquity, memory sometimes was taken to be a property of the soul instead of, or in addition to, organic matter (e.g., Danziger, 2008; Sorabji, 1972) - a view that persisted, though greatly abated, into more modern times.
}

before the present image can be held to stand for a past original. That condition is the fact that the imagined be expressly referred to the past, thought as in the past... But even that would not be memory. Memory requires more than mere dating of a fact in the past. It must be dated in my past. In other words, I must think that I directly experienced its occurrence" (James, 1890, Vol. 1, p. 650; emphasis in original).

One reason memory so often is associated with past-oriented subjectivity is the failure to appreciate that although memory's operations depend on past events, such dependence does not logically warrant the inference that memory, as experienced, is about the past. A failure to separate the how of memory function from the purpose of memory function has led to the common, but logically indefensible, presumption that memory, being of the past, must, of necessity, be about the past.

Thus, our truncated view of memory's temporality derives largely from a failure to appreciate a subtle but crucial difference in the use of two grammatically related prepositions - of and about. While of implies "from" or "due to", about, in a functional sense, implies "for" or "directed toward" (note: About can also be taken to mean "concerning". This is not its functional sense, but rather its referential sense. As we will see in a later section of this paper, memory can refer to the past - e.g., episodic recollection - but this is not its primary evolved function: It does not imply it is for the past). As a result of this conflation, the exception is taken for the rule. This linguistic faux pas is made apparent when questions designed to probe memory's capabilities are complimented with questions about its functionality.

\subsection{To answer the question "what is memory?" One must first appreciate that memory is not a unitary entity}

A consequence of assuming that memory necessarily is "about the past" is that mental events lacking clear connection to pastoriented subjectivity historically have been treated as sub-species, rather than full-fledged aspects of memory. Although most modern taxonomies include these formerly problematic constituents (e.g., semantic and procedural memory), this was not always the case (note: In this paper I deal exclusively with long-term memory).

For example, the memorial status accorded to "knowledge" historically has been inconsistent. This was due in large part to the absence of a pre-reflectively given connection between knowledgeas-experienced and past-oriented subjectivity (i.e., autonoesis; e.g., Tulving, 1985; Tulving, 1985, 2002; Wheeler, Stuss, \& Tulving, 1997) - a connection mandated by memory defined as reacquaintance with the past. ${ }^{2}$ To the extent that knowledge was included in treatments of memory, the focus primarily was on the means by which learning conditions enabled re-acquaintance with previously learned facts, rather than the memorial status or function of those facts per se (e.g., Danziger, 2008; Yates, 1966).

Factual knowledge obviously can refer to the past - e.g., remembering the route to take to find the house I grew up in. However, that knowledge is given to awareness as a "recipe" for locating the house, not as a phenomenological reliving of the past (e.g., Klein, 2013a; Tulving, 1985): Its pastness is inferred from its content rather than pre-reflectively given to awareness (the latter - the experience of reliving past events - is made possible by episodic

\footnotetext{
2 While knowledge obviously can be related to the past, this relation is unlike that found with episodic recollection. In the case of knowledge, relation to the past results either from inference (i.e., given what else I know, $X$ must have transpired at time $T$, where $T$ is prior to the present) or a form of reflection on the content of an occurrent mental state (e.g., remembering one's favorite television show from the 1970s). By contrast, episodic recollection's relation to the past is pre-reflectively given (e.g., Klein, 2013a; Tulving, 1985).
} 
recollection, a unique form of memory that I will discuss in a later section of this paper).

In this sense, knowledge of the past conforms to McTaggart's (1908) "B"-series: i.e., temporality seen as a set of static relations between events: time is frozen into an unchanging pattern of "before and after". Viewed in this way, factual knowledge of the past is, in essence, atemporal. Numeric designators just as easily could be substituted for the "before and after" of events. Whatever temporality facts communicate derives exclusively from interpretation of the meaning of their content. Researchers now take for granted that an individual's repository of facts, language, etc., is a basic constituent of memory. However, this recognition was not firmly established until Tulving's (1972) classic binary division of memory into a semantic and episodic component.

For a very long time procedural memory - i.e., habits and skills (cognitive as well as physical) acquired ontogenetically, that function in the present with an orientation toward the future - also was precariously situated within the domain of memory. The groundwork for its eventual stabilization was not in place until the 19th century, when de Biran (1803/1929) published his classic analysis of the faculties of thought. As was the case for semantic memory, this long delay likely was attributable to the fact that learned skills and habits typically lack experienced reference to one's past: They are performed now is in the service of the next.

Today, most psychologists (e.g., Squire, 2004; Tulving, 1985, 2002; Willingham \& Goedert, 2001) and philosophers (e.g., Bernecker, 2010; Locke, 1971; Michaelian, 2010) view memory as collection of phenomenologically, conceptually, empirically and neurologically separable, but taxonomically related, abilities and dispositions. Among psychologists, this "systems" approach traditionally is seen to originate with Tulving's (1972) division of memory into episodic and semantic components, a classificatory scheme he subsequently expanded to include a procedural component as well (for reviews, Tulving, 1983, 1985; see also Squire, 1987). Whether the constituents of a particular classification scheme are underwritten by similar or different mechanisms is an object of debate (e.g., Foster \& Jelicic, 1999), but the consensus is that a "multiple systems" approach does good theoretical and empirical work. In this academic climate, questions directed at memory are not be considered well-formed unless the target of inquiry admits to multiple instantiation.

\subsection{Memory: a working definition}

So, how do we answer the question "what is it that we call memory?" In its most encompassing form, biological memory (I will not deal with memory exhibited by artifacts, such as computational devices) can be taken as organically-based activity in which information made available to the organism (via perception of the external world or the experience of mental and bodily states) results in an alteration of the neural machinery. To qualify as memory, the alterations must be shown to consistently be associated with changes in the organism's behavior - mental and/or physical - at some point in time following their acquisition.

But that is not enough. A tumor growing in the medulla oblongata certainly qualifies as an alteration in the neural tissue likely to be correlated with mental and physical change (albeit disruptive rather than constructive). To be seen as memory, the changes resulting from alterations in neural tissue must be have a functional relation with a system designed by natural selection to enhance the organism's chances of survival. ${ }^{3}$

\footnotetext{
${ }^{3}$ Every system, by virtue of its specific causal structure, is capable of doing a number of things for which it was not designed (i.e., by-products of adaptation). Memory systems can support activities that are irrelevant (e.g., memorizing $\pi$ to
}

This definition, I believe, is broad enough to accommodate the interests of most modern memory researchers. It is sufficiently open-ended to preclude premature exclusion of potential memory phenomena, yet sufficiently specific to enable the construction of well-formed (i.e., the "right") questions. In addition, it resonates with the historically popular metaphor of memory as a process of inscription - an idea that can be traced from Aristotle's etchedwax tablets (e.g., Sorabji, 1972) to computers (e.g., Norman, 1970) to changes in neural matter detectable by modern radiology (for review, see Draaisma, 2000).

Historical antecedents for this definition are easy to find. Compare Edridge-Green (1897), who on the first page of her text on memory defines it as "the process by means of which the external world and ideas are retained for use on future occasions." (p. 1). Von Feinaigle (1813) expresses a similar view, describing memory as "that faculty that enables us to treasure up, and preserve for future use, the knowledge we acquire" (p. 1). Despite their age, these views have surprising resonance with definitions that populate many modern texts (e.g., Crowder, 1976; Neath, 1998).

\section{Memory and subjective temporality}

So what, if anything, is missing from a definition of memory that is (a) widely held, (b) has a long academic pedigree and (c) has been crafted to capture the concept in only the broadest brush strokes? The answer is subtle but critical. What is missing is an explicit statement of the relation between memory and the mode of subjective temporality it affords. Nor is such a statement found in most definitions of memory (including the few mentioned above: Mention of words such as "on future occasions" in the above definitions is mute with respect to subjective temporal phenomenology; it rather is a statement of the retentive properties of memory). The relation between memory and the past is so intuitive that it often is taken for granted. Why bother to state the obvious?

Memory, by any reasonable definition, is dependent on past events. This, however, does not sanction the conclusion that memory necessarily is about the past. Such an assumption - which characterizes the majority of both ancient and modern views of memory - trades on the logically unjustifiable conclusion that what is of the past must therefore be about the past. Before tackling the merit of this inference (in Sections 4 and 5), let's take a moment to survey the relation between memory and temporality from an historical perspective.

\subsection{The relation between memory and time: a brief historical overview}

The earliest known Western writing on the relation between memory and time is from the 8th century BC. In his Theogony, Hesiod contends that the ability to transcend objective time is made possible by the faculty of human memory (e.g., Cassel, Cassel, \& Manning, 2013), thereby providing the first conception of memory as a mechanism enabling mental time travel. While Hesiod conceptualization was open to temporality in its fullness (i.e., past present and future), Aristotle's (384 BC-322 BC) view was more restricted. In De Memoria he repeatedly makes clear that the concern of memory exclusively is with things past: The object of memory “... is the past, not the future or present, nor what is present as an object of perception or theorizing." (De Memoria, reprinted in Sorabji, 1972,

the first 100 places after the decimal point) or even detrimental (e.g., memories that give rise to post-traumatic stress) to an organism's survival. Accordingly, the products of memory need not promote survival; the only requirement is that they are underwritten by alterations in structures whose evolutionary origins trace to that purpose. 
p. 47). The future is known with the faculty of anticipation, not by memory.

The Aristotelian position dominated intellectual discourse on the relation between time and memory for the nearly two millennia. Thus, we find Saint Augustine (354-430 AD) arguing: "The time of present things past is memory, the time of present things present is direct experience and the time of present things future is expectation." (The Confessions, Book 11, chapter 20, heading 26). Although various emendations to the concept of memory were proposed by medieval Scholastics, the Aristotelian view of its relation to the past served as a stable basis for discourse until modern times.

Things began to change in the late 19th century following Darwin's landmark work on natural selection. Bradley (1887) was among the first to challenge the view that memorial experience was saddled to the past. Based on a functional analysis, he proposed that memory must, of adaptive necessity, be oriented toward the future: "Why is our memory directed toward our incoming sensations and toward the (temporal) side from which change comes?... The answer, in a word, is practical necessity... Life being a process of decay and of continual repair and struggle throughout against dangers, our thoughts, if we care to live, must mainly go the way of anticipation. We are concerned practically with what meets us and what we go to meet, and this practical concern has formed the main habit of our thought." (Bradley, 1887, pp. 581-582; word in parentheses added for textual clarification)

For the next century, the temporal orientation of memory was the subject of numerous philosophical treatments (e.g., Bergson, 1913; Campbell, 1997; De Brigard, 2013; Dokic, 2001; Heidegger, 1997; Husserl, 1964; Kvale, 1974). Most psychologists, by contrast, still uncritically accepted the received view (e.g., Klein, 2013b). But evolutionarily considerations eventually took hold, encouraging some to take seriously the possibility that memory, as a product of natural selection, might be designed to deal not with things past but with contingencies of the "now and the next" (e.g., Boyer, 2009; Dudai \& Carruthers, 2005; Ingvar, 1985; Klein, 2007, in press; Klein, Cosmides, et al., 2002; Klein, Robertson, \& Delton, 2010; Suddendorf \& Corballis, 1997; Tulving, 2002; 2005; Tulving \& Lepage, 2000). 4

\section{Memory from an evolutionary perspective}

Anatomists dissect the organs of the body. Dissection does not entail random cutting; it is a theoretically-driven attempt to divide the body's parts into functional units. While psychologists also perform physical dissection, more often our dissections are of a conceptual nature. In regard to memory, our goal is to dissect the concept into its functional units.

One way to study the functional design of a naturally selected system is to think of it as part of a machine, and then distinguish the machine's capabilities from its functions (e.g., Anderson, 1991; Cosmides \& Tooby, 1992; Klein, 2007; Klein, Cosmides, et al., 2002; Williams, 1966). To specify a machine's function is to specify what it was designed to do. An example taken from Klein, Cosmides, et al. (2002) helps clarify the distinction between capability and function.

Imagine you are presented with a three-hole punch. Having never seen one, you are unsure what it is. Unbeknownst to you, it has been designed to serve a specific function - to put holes in

\footnotetext{
4 This is not to imply that memory is incapable of supporting mental travel into one's past. This clearly is not the case (e.g., Suddendorf \& Corballis, 1997; Tulving, 1985). Indeed, in Section 5 I argue that a form of memory (episodic) unique to Homo sapiens enables us, by virtue of the process of exaptation (e.g., Gould \& Vrba, 1982) to re-experience events from our past (exaptation refers to the process by which a trait, whose origins cannot be traced directly to operation of natural selection (i.e., a by-product), is co-opted by existing machinery for a new, typically adaptive, use; Gould \& Vrba, 1982)
}

writing paper so the paper can be stored in a three-ring binder. If you knew this, it would help you understand why its parts exist in their present form: Why the punch has elements sharp enough to cut paper, why there are exactly three of them, why they form a straight line, and so on. These elements are design features aspects of the machine that are there because they contribute to its function.

Yet every machine, in virtue of having a particular causal structure, is capable of doing an endless series of things it was not designed to do. As many children discover, if you shake a wellused three-hole punch, confetti comes out. The production of small circles of paper is a by-product of the machine's design. None of the parts exist because that arrangement makes confetti. Had the machine been design to make confetti, one might expect more than just three elements, that their shape would be more in keeping with the festivities typically associated with the use of confetti (e.g., star-like rather than round), etc. In short, confetti-making does not explain the presence or arrangement of the punch's parts. Nor do any of the punch's other capabilities - for example, its usefulness as a paper weight. These capabilities are arbitrary with respect to its intended function, by-products of the machine's design (e.g., Barkow, Cosmides, \& Tooby, 1992; Williams, 1966).

The tradition of studying memory by seeing what it is capable of doing - without asking what it was designed to do - is like studying a three-hole punch as if it were a confetti-maker or a paper weight. It is not an effective method for honing in on the set of highly ordered, interlocking elements that embody the systems functional design. An exclusive focus on capability tells us what memory can do, but it does little to help us understand what memory was designed to do. It is like studying the confetti produced by a three-hole punch. Absent a focus on the aspects of design directed by natural selection, we essentially end up studying the "confetti of memory" (although, as we will see in Section 5, in the case of episodic memory, properties that initially may have been by-products can be co-opted by natural selection and acquire functional relevance; e.g., Gould \& Vrba, 1982).

\subsection{The functional aspects of memory}

Memory is a system created by natural selection (e.g., Glenberg, 1997; Howe, 2011; Klein, Cosmides, et al., 2002; Nairne, 2005; Sherry \& Schacter, 1987): It exists in its present form because that arrangement solved certain recurrent problems faced by the organism in its evolutionary past. Evolution does not produce new, complex, metabolically costly phenotypic systems by chance (Dawkins, 1976; Mayr, 2001; Williams, 1966). Such systems acquire their functional organization because that specific design contributed to the organism's ability to survive and reproduce (e.g., Barkow et al., 1992; Howe, 2011; Klein, in press; Mayr, 2001; Nairne, 2005; Sherry \& Schacter, 1987; Williams, 1966).

The origins of vertebrate memory are hypothesized to date to the Cambrian "explosion” (e.g., Ginsburg \& Jablonka, 2007, 2010). This period, which spanned approximately 25 million years beginning around 545 million years ago, is considered one of the most significant transitions in evolutionary history (e.g., Marshall, 2006; Vallentine, 2004): In a relatively short (by evolutionary standards) time essentially all animal phyla first appear in the fossil records (e.g., Vallentine, 2002).

The cause of the Cambrian "explosion" is subject to debate (e.g., changes in the oxygenation or temperature of the biotic environment; for discussion, see Marshall, 2006; Vallentine, 2004). One suggestion is that the astonishing ecological and morphological diversification found during the "explosion" stems from a genetic reorganization of the central nervous system that occurred in parallel among several groups of Cambrian metazoans (e.g., Ginsburg \& Jablonka, 2007, 2010). Of particular relevance to the 
thesis of the present paper, this reorganization is hypothesized to have resulted in the development of neural processes capable of supporting associative learning. The formation and refinement of associative learning (the neural bedrock of modern memory; e.g., Angermeier, 1984), would have made possible numerous behavioral adjustments during an animal's lifetime (Ginsburg \& Jablonka, 2007), which, in turn, would have resulted in a diversity of survivalrelevant adaptations.

For an organism to behave more adaptively at a later time because of experiences at an earlier time, it must be equipped not only with mechanisms that retrieve ontogenetically acquired information, but the ability to direct that information toward environmental contingencies transpiring now and into the future.

Interestingly, the future orientation of memory often is reflected in the terms investigators use to describe the things memory enables an organism to accomplish. For example, Ginsburg and Jablonka (2010), discussing the adaptive significance of associative learning, talk about the benefits of memory for seeking mates, looking for food, reacting to predators, constructing niches, capturing prey, focusing attention, coping with antagonistic interactions, etc. Each proposed function involves adapting to the future, not reexperiencing the past. Yet, despite this (perhaps tacit) recognition of its future-orientation, we persist in interrogating memory with respect to its reproductive accomplishments (recall, recognition, faithfulness to the past, etc.).

On the view I have been pushing, many, if not most, features of memory have been designed by evolution to interface with systems for anticipation and planning (e.g., Bar, 2010; Klein, Cosmides, et al., 2002; Klein, Lax, \& Gangi, 2010; Klein, Robertson, Delton, 2010; Llinas, 2001; Suddendorf \& Corballis, 2007; Tulving, 2005; Tulving \& Lepage, 2000; Young, 1976). As Klein and colleagues observe, “The adaptive function of information storage is intrinsically prospective: It is used to support future decisions and judgments, which cannot be known in advance with certainty. To the extent that the character of subsequent decisions and judgments can be predicted, the memory system can be tailored to flag relevant information and pre-compute variables that are required to make them." (Klein, Cosmides, et al., 2002, p. 313: emphasis added). An evolved capacity to imagine and plan for future contingencies confers an enormous selective advantage on its possessor (Klein, Lax, et al., 2010; Klein, Robertson, et al., 2010; Klein, Roberson, \& Delton, 2011; Suddendorf, Addis, \& Corballis, 2009; Tulving, 2005).

Some have argued that the ability to anticipate future contingencies may be uniquely human (Suddendorf \& Corballis, 1997; Tulving, 1985). Others, taking a more extreme view of non-human temporality, argue that animals are subjectively stuck in the present (e.g., Roberts, 2002, although he allows that chimps may have some limited planning ability).

However, in addition to evolutionary considerations, recent philosophical (Hoerl, 2008) and ethological (Cheke \& Clayton, 2011; Clayton \& Russell, 2009; Finn, Tregenza, \& Norman, 2009; Mulcahy \& Call, 2006; Roberts, 2012) work calls into question the validity of species-specific constraints placed on subjective temporality. If information processing is inherently prospective (and it is; Bar, 2010; Bradley, 1887; De Brigard, 2013; Klein, Cosmides, et al., 2002; Klein, Lax, et al., 2010; Klein, Robertson, et al., 2010; Klein et al., 2011; Suddendorf \& Corballis, 2007; Tulving, 2005), the inability to anticipate future contingencies would be an evolutionary dead-end for animals that depend for their survival (and hence reproductive success) on such fitness-enhancing adaptations. Clearly, this is not the case. All organisms capable of long-term memory are, of adaptive necessity, oriented toward the future. What distinguishes humans from other animals is not the presence of temporal projective abilities, but rather the sophistication of these abilities. The anticipatory and planning skills of humans are more complex, flexible and temporally extensive. They also are more likely to be subject to conscious deliberation (non-humans, by contrast, more likely sense, than consciously consider, the future).

Humans thus are more purposeful and proactive in response to their environment (e.g., Klein, in press; Klein, Lax, et al., 2010; Klein, Robertson, et al., 2010). By virtue of this sophistication, our species, unlike others, can anticipate and plan for future contingencies in a manner that transcends current needs and motivational states (e.g., Bischof-Koehler, 1985; Suddendorf \& Corballis, 2007; but see Cheke \& Clayton, 2010). To require animals to navigate their worlds absent some anticipatory abilities (whether or not they can consciously consider the implications of their future-oriented behavior) would be to render them extinct by definitional fiat (Klein, 2013b).

Accordingly, the most sober conclusion is that all organisms capable of memory are, of necessity, oriented toward the future (e.g., Klein, Cosmides, et al., 2002; Klein, Lax, et al., 2010; Klein, Robertson, et al., 2010). Species-specific differences in future-orientation trade on the complexity and temporal scope of anticipatory and planning abilities, not on their presence or absence (e.g., Bischof-Koehler, 1985; Donald, 1991; Klein, in press; Suddendorf \& Corballis, 1997, 2007).

\section{Memory is of the past but about the future}

From an evolutionary perspective, the function of memory is to aid the organism in anticipating events and deciding the actions to take. These abilities require an orientation toward the future. Life comes at organisms from the future, not from the past, and it is in that direction that our efforts (accompanied by phenomenal and/or access consciousness; e.g., Block, 1998) must be directed. Even responses to present contingencies are necessarily oriented toward the future. So why is the subjective temporality of memory so often assumed to be oriented toward the past?

As I see it, three considerations help account for this temporal misalignment. First, we often conflate the how of memory with the why of memory (see Sections 2 and 3). That is, we assume that the neural mechanisms that mediate memory performance provide direct insight into memory's function. They do not. As discussed in the previous section, we need to draw a sharp conceptual distinction between how a function is instantiated and what the function was designed to accomplish - knowledge of which will help separate those features of memory's design that are relevant to its function from those that support performance of things simply in virtue of the fact that every machine (whether biological or artifactual) has a causal structure (i.e., capabilities that are by-products of design).

Second, we are likely to be disproportionately influenced in our assessment of memory's temporality by its most salient temporal feature - recollective experience. Episodic memory's connection to the past is given to consciousness in a way that procedural and semantic memory are not - it is directly, rather than inferentially, given (e.g., Klein, 2013a; Tulving, 1985). As a wealth of social psychological research has shown, the most salient members of a set have the highest likelihood of having their characteristics taken as properties of the whole (for review see Schneider, 2004). For this reason, orientation toward the past, made possible by episodic memory, can be expected to occupy a position of (inordinate) prominence in our assessment of the memory's mode of temporality.

Third, we need to be mindful of the social origins of most of our attitudes toward remembering (e.g., Nelson, 1989, 1993, 1996). An abundance of evidence demonstrates that when parent (or caregiver) and child begin to talk about previously experienced events (a process that begins almost as soon as the child learns to speak), the parent provides the structure within which to frame the conversation (e.g., Farrant \& Reese, 2000; Fivush, Haden, \&Adams, 1995; 
Nelson, 1993). The child's participation consists largely in repeating and confirming what the parent has said (Haden, 2003). In this way, the parent's attitude toward memory is communicated to the child - an outlook that has a long-term impact on the child's own attitude toward memory (for reviews of the evidence, see Fivush \& Haden, 2003; Nelson, 1989).

With regard to temporal orientation, one feature seen in almost every transcript of parent-child joint reminiscing (despite individual and cultural variation in other aspects of the process; e.g., Hudson, 1990; Engel, 1995; Mullen \& Yi, 1995) is the parent's attempt to locate the child's occurrent mental state (propositional, imagistic, etc.) in the child's past (likely a result of the salience accorded episodic recollection; see point \#2, above). In this way, the sense of memory as necessarily about the past (rather than simply of the past) is communicated from the time the child is able to utter his or her first words. But, and this is the key point, there is no logical or biological reason things must be this way (e.g., Klein, 2013a; Klein \& Nichols, 2012). The prominence accorded the past as the sine qua non of memory's temporal orientation is a product of socialization, not one of nomological necessity.

\subsection{Distinguishing between a system's function and the way in which that function is neurally instantiated}

Memory achieves its evolved function, in part, by storing records of the past. This is accomplished by alterations in nervous tissue. Our metaphors reflect this, likening organic memory artifactual mechanisms for effecting inscription. Historically, interest in trace (e.g., Goldmeier, 1982) and copy theories of memory (e.g.,Draaisma, 2000; Koriat \& Goldsmith, 1996; Roediger, 1980; Earle, 1956; Martin \& Deutscher, 1966) attest to the traction this view has maintained over the centuries. It is largely in virtue of its inscriptive aspect that memory is held to be about the past.

However, as I have argued, the fact that a system accomplishes its goal in a particular manner does not logically warrant the conclusion that the manner of achievement maps on to the nature of the achievement (consider, for example, the issue of multiple realizability; e.g., Klee, 1997). Modern research, particularly radiological, has helped us understand how the mechanisms of memory are instantiated in neural tissue (recent reviews can be found in special issues of NeuroImage, 2012, Bandettini, editor; Cortex, 2013, Moulin, Souchay, \& Morris, editors). But, absent a conceptual framework within which to position the mechanisms thus far uncovered, we are, in essence, driving blind. To understand why those parts take the form they take we need to know not only a machine's structural features, but what those features were designed to accomplish. Evolution provides the framework necessary to situate the "means of accomplishment" within a functional context. And, as argued in Section 4, when considered in this light, memory is best viewed as a physical record of the past in service of the future. As I will argue in Section 6, when viewed from the vantage point of evolved functionality, assumptions about the nature and purpose of the hypothesized inscription (i.e., the physical trace) are seen as in need of reconsideration.

\subsection{Procedural and semantic memory, and their relation to the future}

Given the conflation of the how with the why of memory, and the temporal conceit it encourages, the inconsistent treatment received by procedural memory over the centuries is readily understandable. Its temporality is ambiguous. Although procedural memory is based on learned experience, its function is to enable the organism to deal more effectively with current and future contingencies: That is, it is of the past but about the future.
Semantic memory has suffered similar treatment for similar reasons. While it is undeniable that most, though perhaps not all, our knowledge is acquired ontogenetically (e.g., J. Locke's "tabula rasa"), the function of knowledge is to enable us to better cope with what confronts us. Accordingly, semantic memories are best seen as occurrent mental states whose adaptive significance resides in directing behavior to meet environmental (physical and social) demands. "To behave" necessarily is to orient toward the future; it is about facing and reacting to life as it approaches. In short, while both procedural and semantic memory can, via inference and interpretation (see footnote 2), be related to the past, their mode of subjective temporality is toward the future.

\subsection{The temporal orientation of episodic memory}

All memory experience is occurrent - it is a mental state happening now. As Reid puts it, "Every man can distinguish the thing remembered from the remembrance of it. We may remember any thing we have seen, or heard, or known, of done, or suffered; but the remembrance of it is a particular act of the mind which now exists, and of which we are conscious" (Reid, 1813/1969, pp. 324-325). We can take issue with Reid's insistence that every act of memory is conscious ( this makes sense if and only if memory is, at it typically was, conflated with its episodic component); but every memorybased "act of the mind" certainly takes place in the present. To identify a mental state as a memory, as opposed to, say, an act of imagination, we therefore need to refer the occurrent state to events from the past.

In the case of semantic and procedural memory, this is accomplished via inference or interpretation. The case of episodic memory is more complicated. Unlike semantic and procedural memory, the pastness of episodic recollection is given directly to awareness (e.g., Klein, 2013a). No additional mental gymnastics are required. It thus occupies a unique position among types of memory with regard to its experienced connection to the past (e.g., Klein, 2013a; Tulving, 1985, 2005).

It is unique in another way. Episodic recollection is assumed to be the exclusive property of Homo sapiens (e.g., Baddeley, Conway, \& Aggleton, 2002; Klein, 2013a; Tulving, 1985, 2002). Although some have argued that certain non-human species possess episodic memory (for reviews see Cheke \& Clayton, 2010; Clayton \& Russell, 2009), most investigators feel obliged to acknowledge that, in the absence of a way to determine whether non-verbal beings are capable of autonoesis (i.e., the mental state in which the individual's subjectivity is characterized by “... awareness of re-experiencing here and now something that happened before, at another time and in another place"; Tulving, 1993, p. 68), such abilities are most judiciously characterized as "episodic-like" (for a recent review, see Pause et al., 2013). Whether non-human animals eventually will be shown to experience episodic recollection is presently indeterminable.

Thus, episodic memory, due to its association with autonoetic awareness (e.g., Tulving, 1985, 1993, 2005; Wheeler et al., 1997), provides a direct, pre-reflectively given connection to past experience (Klein, 2013a). Persons possessing autonoetic awareness are capable of re-living experiences in terms of their felt pastness. Episodic memory is the only type of memory to be experientially wedded to the past in a manner satisfying Aristotle's edict.

However, before concluding that episodic memory is unique in its temporal orientation - facing backward rather than forward - it is prudent to consider whether autonoetic awareness, which enables experience of the past, evolved for that purpose. Evolutionary considerations suggest otherwise: "Re-experiencing the past" may not have been the function memory was designed by natural selection to accomplish; rather, this capability may better be viewed as a by-product of the functional design - albeit a 
by-product that subsequently acquired adaptive importance and underwent exaptation.

This makes adaptive sense. Given that nature builds on existing structures, (e.g., Barkow et al., 1992; Dawkins, 1976; Williams, 1966), which, in the case of memory, would have been oriented toward the future, it is likely that autonoetic awareness originally evolved to enhance anticipation and planning by enabling humans (the only creatures believed to possess a self-concept; e.g., Leary \& Tangney, 2012; Snodgrass \& Thompson, 1997) to project themselves into imagined, future-oriented scenarios cf., Tulving's definition of autonoetic awareness as the kind of consciousness that mediates an individual's awareness of his or her existence and identity in subjective time extending from the personal past through the present to the personal future": (Tulving, 1985, p. 1, emphasis not in original; for fuller discussion of autonoesis and self-projection, the reader is referred to Wheeler et al., 1997). The concept of personal survival is, by definition, self-referential. To the extent an organism can consciously insert itself into scenarios directed toward the future, its prospects for survival are thereby improved (Klein, 2012). Episodic memory, with its intimate connection to self-referential cognition (e.g., Conway, 2005; Prebble, Addis \& Tippet, in press; Tulving, 1983; Wheeler et al., 1997; for review see Klein \& Gangi, 2010) is ideally suited to such a challenge.

Thus, the case can be made that episodic memory's evolved function was not to recollect events of the past, but to enhance our ability to navigate the environment by imagining ourselves in future-oriented scenarios. Indeed, a major growth industry within contemporary psychology is specifically devoted to the forms of future-oriented mental time travel enabled by episodic memory (e.g., Addis, Cheng, Roberts, \& Schacter, 2011; Addis, Wong, \& Schacter, 2007, Botzung, Denkova, \& Manning, 2008; Buckner and Carroll, 2007; Busby \& Suddendorf, 2005; Cooper, VarghaKhadem, Gadian, \& Maguire, 2011; Hassabis, Kumaram, Vann, \& Maguire, 2007; Klein, Loftus, \& Kihlstrom, 2002; Kwan, Carson, Addis, \& Rosenbaum, 2010; Mullally, Hassabis, \& Maguire, 2012; Race, Keane, Verfaellie, 2011; Szpunar, Watson, \& McDermott, 2007; for recent reviews, see Addis \& Schacter, 2012; Klein, 2013a; Suddendorf, 2010; Szpunar, 2010).

What then is the evolved function of episodic recollection? Clearly what matters, from the standpoint of survival, is not what happened in the past, but what we now face and how we respond. We remember the past so we can learn from it. But that learning is experienced occurrently; and while the content of that learning may make reference to the past, not much is gained from an evolutionary or logical standpoint from re-experiencing its acquisition. (The dog, drooling in agitated anticipation in response to the conditioned stimulus for its next meal, is not oriented toward the conditions of acquisition; rather it is oriented toward the meal it expects to soon be present).

In fact, with regard to the content of a remembered event, there is no principled (or empirical) reason to suppose that semantic memory cannot and does not make available the same memory content (who, what, where and when) as does episodic memory (for discussion, see Klein, 2013a; Klein \& Nichols, 2012). It is the utility of the knowledge provided by that content - not the pre-reflective feeling of re-living the circumstances in which it initially was acquired (i.e., autonoetically given to awareness) - that appears necessary for adaptive behavior.

So, where does this leave the relation between episodic memory and past-oriented subjectivity? If, as proposed, autonoetic awareness initially evolved to facilitate our ability to cope with future contingencies, the capacity to mentally travel into one's past may be a by-product of the system - one that subsequently was co-opted by the process of exaptation (for a similar view, see Tulving, 2005). There are advantages to being consciously aware not only of the "now and the next", but also of events that took place minutes, weeks or years earlier (for discussion and related empiricism, see Klein, Cosmides, Tooby \& Chance, 2001; Klein, Cosmides, et al., 2002; Klein, Loftus, et al., 2002; Klein, Cosmides, Gangi, Jackson, Tooby \& Costabile, 2009; Tulving, 2005). Most of the advantages identified thus far have to do with the social aspects of life (self-knowledge, personal identity, self-continuity, interactions taking place in the social environment; e.g., Boyer, 2009; Klein et al., 2001, 2009; Klein \& Gangi, 2010), lending credence to the suggestion that the recollective function of episodic memory may have been co-opted as a result of social pressures (Klein, Cosmides, et al., 2002; Klein et al., 2009). If the pattern of discovery stays true to course, episodic recollection ultimately may come to be viewed as an exaptation in the service of refining our abilities to maneuver within the remarkably complex social structures unique to humans (e.g., systems of laws, politics, relations, education, culture, etc.).

\section{Implications}

Although most psychologists still subscribe (implicitly or explicitly) to the traditional view of memory as oriented toward the past, things have begun to change. For example, Nairne's (2005, 2010) advocacy of memory as a system evolved to enhance survival (clearly a future-oriented enterprise; e.g., Klein et al., 2011) has resulted in a highly active program of research exploring the effects of encoding conditions (survival versus non-survival) on measures of retention (e.g., Burns, Hwang, \& Burns, 2011; Butler, Kang, \& Roediger, 2009; Kang, McDermott, \& Cohen, 2008; Klein, 2012; Klein, Lax, et al., 2010; Klein, Robertson, et al., 2010, Klein et al., 2011; Kroneisen \& Erdfelder, 2011; Nairne \& Pandeirada, 2008; Nairne, Pandeirada, Gregory, \& Van Arsdall, 2009; Otgaar, Smeets, \& van Bergen, 2010; Soderstorm \& McCabe, 2011; Weinstein, Bugg, \& Roediger, 2008; for recent reviews, see Howe \& Otgaar, 2013; Klein, in press). Another approach to memory that emphasizes its futureoriented aspects is that of memory in its prospective capacities (for review, see Brandimonte, Einstein, \& McDaniel, 1996). However, despite espoused concern with memory in relation to the future, both of these programs rely heavily on measures designed to assess the retrospective properties of memory (e.g., differences in retention associated with task manipulations) with almost no attention given to the behavioral concomitants of adaptive functionality e.g., how plans are constructed from memory; that is, how different systems of memory, belief, expectations, imagination and goals work together to anticipate and respond to survival needs, etc.

That a focus on memory as "about the past" still is the norm is put in sharp relief by Hoerl and McCormack's (2001) edited volume "Time and Memory". Of approximately 400 pages only about 13 are devoted to considering the relation between memory and futureoriented cognition. By contrast, more than half of the chapters are specifically concerned with memory in relation to the past (e.g., "Memory, Awareness and the Past" and "Knowledge and the Past").

A slightly more recent volume on the same topic (Parker, Crawford, \& Harris, 2006) presents a somewhat more encouraging picture. Two of the 16 chapters are explicitly addressed to the future-orientation of memory, while several others at least mention the theme. Sill, a heavy dose of past-oriented temporality remains on display (e.g., "inscribing and forgetting", "memory traces", "retention", "remembering the past", etc.). Nonetheless, the more visible role accorded future-oriented memory is, in my view, a positive development.

One area does show considerable promise for an eventual re-evaluation of memory's temporal priorities is research on future-oriented mental time travel (FMTT). As noted earlier, this is a topic of great interest to both cognitive psychologists and neuroscientists, with more than 100 papers appearing the in just the past 5 years! In contrast to the disconnection between orientation and assessment evidenced by studies of adaptive and 
prospective memory, the majority of studies of FMTT rely on analysis of participant-generated reports of imagined, futureoriented scenarios (for review see Szpunar, 2010). In this way, the future-orientation of memory is addressed directly rather than via measures of the remembrance of things past. We may be witnessing the beginning of research programs embracing the view that memory is about the future.

An intriguing possibility that draws support from an evolutionary analysis of memory is that memory enabled humans to become aware of the future before they knew about the past. Since memories do not leave any fossil record, this must remain little more than speculation. However, whether or not this proposal is correct, an appreciation of the inherently future-oriented nature of memory afforded by the theory of natural selection is essential for increasing the odds that the questions we put to nature are questions of the "right" type. ${ }^{5,6}$

\subsection{The "truth" of declarative memories}

An important focus of memory research, with roots in antiquity (e.g., Danziger, 2008; Yates, 1966), concerns the extent to which the content it makes available to awareness captures the objects and events they are presumed to represent. We thus find questions about whether a memory is a copy of the past, a direct acquaintance with the past, an inscription or trace in neural matter, the veridicality of the material retrieved, etc. (e.g., Earle, 1956; Furlong, 1951; Goldmeier, 1982; Locke, 1971; Schacter, 1995; Sutton, 1998).

Consider for example, the question of "false memory" (for classic reviews, see Roediger, 1996; Schacter, 1995). Setting aside the logical impossibility of assessing the fidelity of the represented to that which it represents (for discussion, see Furlong, 1951), ${ }^{7}$ evolutionary analysis suggests the merit of such a determination, from an evolutionary perspective, is dubious at best (e.g., Boyer, 2009). Evolution trades in functionality, and functionality requires only that memory work as designed, not that it remain faithful to some hypothesized object or event from one's past. If what is remembered is sufficient to get the job done (e.g., to anticipate or plan for future contingencies), how it gets the job done is of considerably less concern (at least to nature; scientists are likely to feel otherwise).

\footnotetext{
5 There clearly can be reasons to know what happened $10 \mathrm{~min}, 10 \mathrm{~h}, 10$ days, 10 months or 10 years ago. But knowing when something happened does not require experiencing that knowledge as part of the past. This can occur - inferentially (in the case of semantic memory) and pre-reflectively (in the case of episodic memory). But the facts to which the knowledge refers do not have to be phenomenologically given as past. From a functional perspective, all they need is to be occurrently known as referring to the past. And even the act of "knowing remembered events are from the past" often is not necessary for achieving one's goal. For example, I can retrace my steps in memory to recover my lost keys. But to accomplish my objective (key recovery), the knowledge occupying awareness need not be experientially placed in the past or even inferentially referred to the past. It simply needs to provide an atemporal schema or recipe I can use to guide my search for the lost key. I can reconstruct my acts of the past as being in the past, but this serves no adaptive purpose beyond locating the reconstruction in its proper temporal context (i.e., the keys I lost today, not yesterday or the day before).

${ }^{6}$ Questions of "truth" must, of logical necessity, be restricted to the declarative systems of memory. Procedural memory, lacking propositional representation, is formally precluded from considerations truth.

7 To assess the degree to which an object of experience recaptures the original object as experienced, we need to compare the two. But to do so requires we already have access to the past object or event. If the object of comparison exists in the mind, a memorial representation appears to be superfluous (e.g., Locke, 1971). If, instead, a physical record of the original object or event exists, a non-redundant comparison can be made. However, to determine whether the physical record is the correct object of comparison requires we remember its past status (e.g., is this the relevant written record, is this the intended photograph?). Identifying the physical object of comparison thus depends on memory, thereby begging the question: i.e., assuming what one it trying to prove.
}

On this view, there is no principled reason for memory to adhere to any particular degree of faithfulness to the past; all that matters, from a functional perspective, is that the information memory supplies is beneficial to the adaptive demands placed on the organism. Indeed, recent treatments of "false memory" have begun to attribute many distortions to the operation of adaptive processes, rather than to some flaw inherent in the system (for recent review see Schacter, Guerin, \& St. Jacques, 2011).

This is not to say that memory content is unconstrained. To effectively and reliably solve problems, memory must maintain some degree of fidelity to the past. It would do no good to recollect a blue elephant with angel's wings if a person was relying on memory to locate a parked car. Nonetheless, within fairly wide parameters, the content served up to consciousness need not entail "precision of match" as a criterion of success.

That memory is a system for solving problems (e.g., Klein, Cosmides, et al., 2002), rather than reproducing past with fidelity, is clearly reflected in the conception of memory as re-constructive rather than re-productive - an idea pioneered by Bartlett (1932) and now taken as axiomatic. The notion that memory does not consists in uniquely specifiable, self-contained traces, but rather is a creative effort involving acts of expectation, imagination, belief and other cognitive abilities also is seen in research showing that recollection consists in a variety of functionally independent subsystems that contribute the "who", "what", "where" and "when" to the "unified" product given to consciousness (e.g., Klein, German, Cosmides, \& Gabriel, 2004; McCarthy \& Warrington, 1992).

Viewing memory as related to, and perhaps inseparable from, acts of imagination, thought, etc., also helps explain traditional difficulties encountered when one attempts to provide a set of norms by which to differentiate memory from other cognitive functions. For example, over the years numerous criteria have been proposed for differentiating memory from non-memorial mental content. Hume argued that the vivacity of a mental image is a basis by which we separate an image or thought from a memory, with memory being more lively and vivacious (Hume, 1748/2004). Russell saw things differently, arguing that to be considered memory a mental content must be accompanied by two feelings - pastness and familiarity (e.g., Russell, 1921). Among modern psychological investigators, the work of Johnson and colleagues represents the most systematic attempt to tackle this vexing problem (for a review see Johnson, Hashtroudi, \& Lindsay, 1993). Their research eventuated in a set of criteria for identifying a mental experience as a memory - e.g., the richness of the contextual and perceptual elements contained in a mental state.

Unfortunately, as most theorists and practitioners have discovered, none of these criteria stand the test of logical analysis or introspection (for reviews, see Bernecker, 2010; Casey, 1977; Furlong, 1951; Warnock, 1987). For example, Russell's assumption that the content of memory experience is "bound to the past" is undermined by demonstrations that memorial experience is, at least to a degree, reconstructive (e.g., Bartlett, 1932). And, we all have had experiences in which an imagination is vivid and a memory faint. As Bernecker (2010) concludes, the problem with the memory-markers thus far proposed is that "they don't offer a reliable mark" (p. 22). However, this need not concern us if memory is construed as a functionally related, interacting set of cognitive abilities rather than a fixed inscription in neural matter (e.g., De Brigard, 2013; Klein et al., 2004; Schacter, 2012). Memory and imagination may be so difficult to disentangle because there is no clear conceptual (e.g., Klein, 2013b; Schacter, 2012) or neurological (Mullally \& Maguire, in press) line of demarcation.

This brings me to the topic of considerable contemporary interest - memory and neuro-imaging. While space requirements placed on Target Articles prevent extended discussion, suffice it to note that the views I presented have implications for radiological 
efforts at identifying the neural substrates of memory. To the extent memory is not a trace, copy or inscription, then, as Lashley (1950) was forced to concede following years of study, there may be no "memory trace" to be found. Nothing in the existing imaging literature makes a strong case to the contrary (e.g., Klein, 2010; Klein, Lax, et al., 2010). The fact that scientists have an abstract category does not guarantee that an ontological correlate exists in the brain. Unless the questions we pose to nature are the "right" questions, we run the risk of answers that take us in the wrong direction.

\subsection{What are we supposed to be doing if not measuring retention?}

One reviewer argued that throughout this paper I have made the "mistake" of assuming that just because researchers "assess the retrospective properties of memory" means "that they believe memory is oriented toward the past". He laments "Just what kind of memory research are we supposed to be doing?" This is a fair question and one that many readers likely share. I offer some thoughts and suggestions below.

I am not convinced that the future-orientation of memory is fully appreciated (e.g., my historical review). Despite the practical aspects of assessing memory via its retrieval activities (which, by definition, take place in the present), it is far from obvious that most investigators recognize that the retentive aspects of memory are not its core features. The act of remembering almost universally is assessed with regard to such properties as the amount and order of content retrieved and the veracity with which that content tracks the past.

But, as I have argued, adopting an evolutionary perspective calls to question the usefulness of this approach. With regard to adaptive significance, memory is not in the service of representing the "truth" (as though the truth is epistemologically verifiable!). Memory does not work because it tracks the truth - it works because it "does good work" for us, even if (by some criterion) it can be shown to be false (and, one cannot determine the veracity of a memory absent reliance on some other form of memory, thereby begging the question. Since, discussion of this point would take us too far afield, I direct the interested reader to Furlong, 1951).

Our focus on the amount, order and accuracy of retention (and similar past-oriented measures) is a relatively modern concern. For much of human history, memory was not assumed to behave in a strictly reproductive manner. For example, as used in oral tradition, it was required only to enable an acceptable recitation of some ballad or tale, allowing ample room for improvisation. It was not until much later, when memory metaphors began to track the inscription technologies that accompanied increasing literacy and mechanical sophistication, that a premium began to be placed on memory as a system for precise reproduction (e.g., Danziger, 2008; Yates, 1966). But, this, I have argued (and history, to a degree, corroborates), was not its evolved purpose.

These considerations have obvious resonance with the idea of memory as reconstruction rather than reproduction, an idea traceable to Bartlett (1932) but now part of the fabric of most researchers' (often implicit) assumptions about their target of inquiry. I say "implicit" because despite this acknowledged "fact" about memory, we still show a disproportionate concern with measures of memory designed to assess its ability to capture the past (e.g., measure of amount, order, fidelity, etc.), as well as variables that influence that ability (e.g., amount of delay, level of processing, etc.).

This is not to say that such considerations are uninformative; they are helpful - to a degree. But, if one wants to understand the features of a system put in place by natural selection, one needs to focus on those aspects of the system that map its functionality - i.e., the adaptive task(s) for which it was selected (as noted, this is starting to occur - e.g., Schacter et al., 2011). Once we more fully appreciate the extent to which memory is oriented toward the "now and the next", measures such as the fidelity will take a second seat to measures that address future-directed functionality. We see this in the recent work on future-oriented mental time travel, where participants are asked to do such things as construct scenarios illustrating their plans and anticipations. Neither amount remembered (in the process of construction) nor the veracity of the content retrieved is an essential consideration: What is of interest is how these constructions enable their constructor to better conceptualize and deal with what he or she believes is likely to be encountered.

The traditional memory research context - in which measures of retention serve as the dependent measure - also needs to take into consideration the goal-oriented, social nature of the testing situation. From the investigator's point of view, the participant is presented with a list of words, or whatever, and then, after the passage of some interval, asked to reproduce or recognize the items presented. But, from the participant's perspective, the testing context is an ongoing social interaction with a clear goal - she or he is being asked engage in future-oriented behavior (e.g., the act of recollection) to satisfy the social contract into which he or she has entered. Veracity/amount of output is one consideration, but an analysis of the participant's perceived goals, methods of achieving those goals, assessing their level of attainment, and the effects on social status that result from entering into the social contract we call the "experimental situation" (all having to do with the future) need greater consideration and empirical attention. Memory cannot be divorced from its functional context.

Memory often is described as complex (e.g., Foster \& Jelicic, 1999). It is, but not only for the reasons typically given (e.g., multiple stages and systems). It is also complex because it is an organismic function wedded to expectation, planning, anticipation, prediction, contingency management, navigating social interactions, self-definition, imagination, creativity, goals, beliefs, actions, etc.; in short, it is concerned with understanding "what is, and what to do about it" (e.g., Klein, 2007). It is a response to environmental contingencies and internal states by which the organism positions itself to deal with consequences (real or imagined) placed in its path.

Until we take this aspect of complexity into account in our experimental analyses, we will have taken only a small step from that which we proudly proclaim "modern memory research" has successfully distanced itself - i.e., the Ebbinghaus tradition. Certainly some separation has been achieved: We now acknowledge factors such as meaning and reconstruction. However, we still focus largely on measures of retention, while ignoring the futureoriented, often goal-based, functions that situates memory in its evolved context.

New measures and methods that address these adaptive concerns are needed. While the details mostly remain to be worked out, knowing what needs to be addressed provides the direction needed to formulate the "right" questions. The future-oriented mental time travel literature provides some suggestions (e.g., scenario construction, schema-based planning), but other measures tapping participants' goals, beliefs, construals, anticipations, solutions (mental and physical), etc. must be addressed. ${ }^{8}$

\footnotetext{
${ }^{8}$ It often has been observed that many "functions' of memory are now being downloaded onto cultural technologies (e.g., computers, printed records, etc.; e.g., Donald, 1991). But it is only by appreciating the future-orientation of human memory that we can even begin to understand how culture has become a human reality.
} 


\section{Final thoughts}

In recent years the idea that memory, at least in part, is oriented toward the future has become a topic of interest (witness the explosion of work on FMTT). Leading the way are Dan Schacter (2012; Schacter, Addis, Hassabis, Martin, Spreng, \& Szpunar, 2012), Suddendorf and Corballis (2007), Hans Markowitsch (Markowitsch \& Staniliou, 2011) and several others (e.g., De Brigard, 2013; Dudai \& Carruthers, 2005; Howe, 2011). However, since the pioneering insights of Bradley (1887), the present paper is the first of which I know - with two important exceptions: Boyer $(2009)^{9}$ who, in discussion of the evolved functions of episodic recollection, presents ideas bearing a clear relation to those proposed herein, and Tulving (2005), whose ideas I present below - to take the next step and argue that memory, as designed by natural selection, is not simply capable of imagining the future; rather imagining the future is its evolved function, its raison d'être.

With respect to the "insights" I have "uncovered", Tulving, as so often is the case, is way ahead of the curve. With his characteristic combination of precision and clarity, Tulving, in a personal communication (6/4/13), summarizes in a few paragraphs what I have taken pages to communicate.

"All forms of learning and memory, from the lowliest to the highest, serve very much the same function as do the 'instincts': They provide the organisms with means of behaving more effectively than would have been possible in the absence of the relevant acquired knowledge or skill. An organism learns something today to behave more effectively in the future. In this sense, when learning occurs, it is oriented to the future; when its fruits are subsequently used, the memory is oriented to the present. The important criterion in judging the worth of any act of learning or memory has to do with their usefulness in guiding ongoing activity here and now.

Thus, all forms of learning and memory known throughout the whole animal kingdom could be said to be 'proscopic', a term derived from Greek that means 'forward-looking'. From sensitization and habituation, through simple and complex classical and instrumental conditioning, through the learning of perceptualmotor and cognitive skills, through various forms of 'implicit' memory, such as priming, through the imitative learning that occurs in higher animals, all the way to the immense quantities of concrete and abstract knowledge of the world that adult human beings have accumulated throughout their lives, memory is proscopic: it is important solely because it shapes and effectively enhances the organism's interaction with its future environment.

This basic truth holds as much for Aplysia learning to withdraw its gill to a conditioned stimulus, the mouse learning the location of the sunken platform in a Morris water maze, for the monkey remembering the location of the peanut in a delayed nonmatching-to-sample task, the child avoiding touching the hot stove, the pinch hitter hitting the ball out of the ball-park, the Scrabble player coming up with a clever word that astounds the opponents, the scientist thinking of a new kind of a distinction that is important in the study of the brain/mind, and so on, and on, and on, essentially ad infinitum.

In none of these future-oriented learning situations and presentoriented memory situations does I matter how the knowledge was acquired. There is no necessity for any conscious access to the past, and no necessity to be consciously aware of past experiences. The only thing that matters is the efficacy of the current behavior. The

\footnotetext{
${ }^{9}$ I was not aware of Boyer's (2009) chapter until after writing the initial version of the present manuscript. Dan Schacter brought it to my attention. While we focus on somewhat different questions, I think the overlap between papers is a good sign: Apparently, once one takes seriously an evolutionary view of memory, the conclusions are both necessary and compelling.
}

child does not remember where and how she touched the hot stove in the past, but she knows how to treat the stove now; the amnesic patient does not remember that the examining physician hid a pin in his hand while shaking the patient's hand an hour ago, but she knows that it is not good to shake the doctor's hand now; the contestant in a TV show does not remember when or where or how she acquired the knowledge that Hannibal is associated with elephants, but she answers the question correctly and profitably now. Because all these people can efficiently rely on their proscopic memory, remembering the past is irrelevant.

Thus, despite the traditional association between memory and the past, the remembering of the past, in the sense of conscious recollection of what happened on an earlier occasion, does not play any critical role in making use of what has been learned and how the fruits of that learning are used. Sometimes, of course, the expression of acquired skills and knowledge is accompanied by conscious recollections of past experiences, but these occurrences are epiphenomenal only. The circumstances surrounding the origin and creation of knowledge that guides effective behavior may be of interest to the scientist studying such behavior, but to the behaving organism it makes no difference.

The singular exception to all the ubiquity and evolutionary significance of proscopic forms of learning and memory that serve the future without bothering about the past is episodic memory. Episodic memory does exactly what other forms of memory do not and cannot do - it makes it possible for the individual to recollect previously experienced events as such. It enables the individual to mentally 'travel back into her personal past.' It shares with proscopic memory the basic function - it provides the individual with useful information as to the effective courses of actions in various situations-but it goes beyond the proscopic function in that it does allow us to remember (to consciously recollect) what happened in the past. A child remembers what happened at a friend's birthday party the day before, a young lover remembers the expression on the beloved's face in the moonlight, the scientist remembers the first time when a speaker at a conference mentioned her name and work, and so on, and on. Because episodic memory is oriented toward the past, we can think of episodic memory as 'palinscopic' (backward-looking) memory. An individual who 'possesses' palinscopic memory can at Time 2 'mentally travel back' to Time 1." (a fuller treatment can be found in Tulving, 2005). ${ }^{10}$

Tulving's insights express with his unique clarity and concision much of what I have struggled to communicate in this paper: Memory - with the (possible) exception of episodic recollection - is of the past (its acquisition), in the present (its experience) and about the future (its temporal orientation).

\section{References}

Addis, D. R., \& Schacter, D. L. (2012). The hippocampus and imaging the future: Where do we stand? Frontiers in Human Neuroscience, 5. Article 173.

Addis, D. R., Wong, A. T., \& Schacter, D. L. (2007). Remembering the past and imagining the future: Common and distinct neural substrates during event construction and elaboration. Neuropsychologia, 45, 1363-1377.

Addis, D. R., Cheng, T., Roberts, R. P., \& Schacter, D. L. (2011). Hippocampal contributions to the episodic simulation of specific and general future events. Hippocampus, 21, 1045-1052.

Anderson, J. R. (1991). Is human cognition adaptive? Behavioral and Brain Sciences, $14,471-517$.

\footnotetext{
10 While Tulving's insights may appear to place undue emphasis on the backwardlooking aspects of episodic recollection, I do not think this is the message he wishes to convey (personal communication); rather, the past-oriented aspect of episodic memory is the exception that proves the rule. And, as previously noted, within the domain of episodic memory, the future-orientation provided by this system of longterm memory is (a) well-established, and (b) quite possibly the aspect of episodic memory that initially was selected for.
} 
Angermeier, W.F.(1984). The evolution of operant learning and memory. Paris, France: Karger.

Baddeley, A., Conway, M., \& Aggleton, J. (2002). Episodic memory: New directions in research. Oxford, UK: Oxford University Press.

Bandettini, P.(Ed.).(2012). Special Issue: 20 years of fMRI. NeuroImage, 62, 575-1324

Bar, M. (Ed.). (2010). Predictions and the brain: Using our past to generate a future. New York, NY: Oxford University Press.

Barkow, J. H., Cosmides, L., \& Tooby, J. (Eds.). (1992). The adapted mind: Evolutionary psychology and the generation of culture. New York, NY: Oxford University Press.

Bartlett, F. C. (1932). Remembering. London, UK: Cambridge At The University Press. Bergson, H. (1913). Matter and memory. London, UK: George, Allen, \& Unwin Ltd.

Bernecker, S. (2010). Memory: A philosophical study. Oxford, UK: Oxford University Press.

Bischof-Koehler, D. (1985). On the phylogeny of human motivation. In L. H. Eckensberger, \& E. D. Lantermann (Eds.), Emotion and reflexivity (pp. 3-47). Vienna, Austria: Urban \& Schwarzenberg.

Block, N. (1998). On a confusion about a function of consciousness. In N. Block, O. Flanagan, \& G. Guzeldere (Eds.), The nature of consciousness: Philosophical debates (pp. 375-415). Cambridge, MA: The MIT Press.

Botzung, A., Denkova, E., \& Manning, L. (2008). Experiencing past and future personal events. Functional neuroimaging evidence on the neural basis of mental time travel. Brain and Cognition, 66, 202-212.

Boyer, P. (2009). What are memories for? Functions of recall in cognition and culture. In P. Boyer, \& J. V. Wertsch (Eds.), Memory in mind and culture (pp. 3-28). Cambridge, UK: Cambridge University Press.

Bradley, F. H. (1887). Why do we remember forwards and not backwards? Mind, 12 579-582.

Brandimonte, M., Einstein, G. O., \& McDaniel, Ma. A. (1996). Prospective memory: Theory and applications. Mahwah, NJ: Lawrence Erlbaum Associates.

Buckner, R. L., \& Carroll, D. C. (2007). Self-projection and the brain. Trends in Cognitive Sciences, 11, 49-57.

Burns, D. J., Hwang, A. J., \& Burns, S. A. (2011). Adaptive memory: Determining the proximate mechanisms responsible for the memorial advantage of survival processing. Journal of Experimental Psychology: Learning, Memory, and Cognition, 37, 206-218.

Busby, J., \& Suddendorf, T. (2005). Recalling yesterday and predicting tomorrow. Cognitive Development, 20, 363-372.

Butler, A. C., Kang, S. H. K., \& Roediger, H. L., III. (2009). Congruity effects between materials and processing tasks in the survival processing paradigm. Journal of Experimental Psychology: Learning, Memory, and Cognition, 35, 1477-1486.

Campbell, J. (1997). The structure of time in autobiographical memory. European Journal of Philosophy, 5, 105-118.

Casey, E. S. (1977). Imagining and remembering. Review of Metaphysics, 31, 187-209.

Cassel, J.-C., Cassel, D., \& Manning, L. (2013). From Augustine of Hippo's memory systems to our modern taxonomy in cognitive psychology and neuroscience of memory: A 16-century map of intuition before light of evidence. Behavioral Science, 3, 21-41.

Cheke, L. G., \& Clayton, N. S. (2010). Mental time travel in animals. WIREs Cognitive Science, 1, 1-16.

Cheke, L. G., \& Clayton, N. S. (2011). Eurasian jays (Garrulus glandarius) overcome their current desires to anticipate two distinct future needs and plan for them appropriately. Biological Letters, http://dx.doi.org/10.1098/rsbl.2011.0909

Clayton, N. S., \& Russell, J. (2009). Looking for episodic memory in animals and young children: prospects for a new minimalism. Neuropsychologia, 47, 2330-2340.

Conway, M. A. (2005). Memory and the self. Journal of Memory and Language, 53, 594-628.

Cooper, J. M., Vargha-Khadem, E., Gadian, D. G., \& Maguire, E. A. (2011). The effect of hippocampal damage in children on recalling past and imagining new experiences. Neuropsychologia, 49, 1843-1850.

Cosmides, L., \& Tooby, J. (1992). Cognitive adaptations for social exchange. In J. Barkow, L. Cosmides, \& J. Tooby (Eds.), The adapted mind: Evolutionary psychology and the generation of culture (pp. 163-228). New York, NY: Oxford University Press.

Crowder, R. G. (1976). Principles of learning and memory. Hillsdale, NJ: Lawrence Erlbaum Associates.

Danziger, K. (2008). Marking the mind: A history of memory. Cambridge, UK: Cambridge University Press.

Dawkins, R. (1976). The selfish gene. Oxford, UK: Oxford University press

de Biran, M. (1803/1929). The influence of habit on the faculty of thinking. Baltimore MD: The Williams \& Wilkins Company.

De Brigard, F. (2013). Is memory for remembering? Recollection as a form of episodic hypothetical thinking. Synthese, http://dx.doi.org/10.1007/s11229-013-0247-7

Dokic, J. (2001). Is memory purely preservative? In C. Hoerl, \& T. McCormack (Eds.) Time and memory: Issues in philosophy and psychology (pp. 213-232). Oxford, UK Clarendon Press.

Donald, M. (1991). Origins of the modern mind: Three stages in the evolution of culture and cognition. Cambridge, MA: Harvard University Press.

Draaisma, D. (2000). Metaphors of mind: A history of ideas about the mind. New York, NY: Cambridge University Press.

Dudai, Y., \& Carruthers, M. (2005). The Janus face of Mnemonsyne. Nature, 434, 567.

Earle, W. (1956). Memory. The Review of Metaphysics, 10, 3-27.

Ebbinghaus, H.(1885/1913). Memory: A contribution to experimental psychology. New York, NY: Teacher's College, Columbia University (Translated by H.A. Ruger \& C. Bussenius).

Edridge-Green, F. W. (1897). Memory and its cultivation. New York, NY: D. Appleton and Company.
Engel, S. (1995). The stories children tell: Making sense of the narrative childhood. New York, NY: W.H. Freeman.

Farrant, K., \& Reese, E. (2000). Maternal style and children's participation in reminiscing: Stepping stones in children's autobiographical memory development. Journal of Cognition and Development, 1, 193-225.

Faye, J. (1989). The reality of the future. Odense, Denmark: Odense University Press.

Finn, J. K., Tregenza, T., \& Norman, M. D. (2009). Defensive tool use in a coconut carrying octopus. Current Biology, 19, R1069-R1070.

Fivush, R., \& Haden, C. A. (2003). Autobiographical memory and the construction of a narrative self. Mahwah, NJ: Lawrence Erlbaum Associates.

Fivush, R., Haden, C. A., \& Adams, S. (1995). Structure and coherence of preschooler's personal narratives over time: Implications for childhood amnesia. Journal of Experimental Child Psychology, 60, 32-56.

Foster, J. K., \& Jelicic, M. (1999). Memory: Systems, process, or function? New York, NY: Oxford University Press.

Furlong, E. J. (1951). A study in memory. New York, NY: Thomas Nelson and Sons Ltd

Ginsburg, S., \& Jablonka, E. (2007). The translation to experience: Limited learning and limited experiencing. Biological Theory, 2, 218-230.

Ginsburg, S., \& Jablonka, E. (2010). The evolution of associative learning: A factor in the Cambrian explosion. Journal of Theoretical Biology, 266, 11-20.

Glenberg, A. M. (1997). What memory is for. Behavioral and Brain Sciences, 20, 1-55.

Goldmeier, E. (1982). The memory trace: Its formation and its fate. Hillsdale, NJ: Lawrence Erlbaum Associates.

Gould, S. J., \& Vrba, E. (1982). Exaptation-A missing term in the science of form Paleobiology, 8, 4-15.

Haden, C. A. (2003). Joint encoding and joint reminiscing: Implications for young children's understanding and remembering of personal experiences. In R. Fivush, \& C. A. Haden (Eds.), Autobiographical memory and the construction of a narrative self (pp. 49-69). Mahwah, NJ: Lawrence Erlbaum Associates.

Hassabis, D., Kumaram, D., Vann, D. S., \& Maguire, E. A. (2007). Patients with hippocampal amnesia cannot imagine new experience. Proceedings of the National Academy of Sciences of the United States of America, 104, 1726-1731.

Heidegger, M. (1997). Kant and the problem of metaphysics (5th ed.). Bloomington, IN: Indiana University Press (Translated by R. Taft)

Heisenberg, W. (1958/1999). Physics and philosophy. Amherst, NY: Prometheus Books.

Herrmann, D. J., \& Chaffin, R. (1988). Memory in historical perspective: The literature before Ebbinghaus. London, UK: Springer-Verlag.

Hoerl, C. (2008). On being stuck in time. Phenomenology and the Cognitive Sciences, 7, 485-500.

Hoerl, C., \& McCormack, T. (2001). Time and memory: Issues in philosophy and psychology. Oxford, UK: Clarendon Press.

Howe, M. L. (2011). The nature of early memory. New York, NY: Oxford University Press.

Howe, M. L., \& Otgaar, H. (2013). Proximate mechanisms and the development of adaptive Memory. Current Directions in Psychological Science, 22, 6-22.

Hudson, J. A. (1990). The emergence of autobiographical memory in mother-child conversation. In R. Fivush, \& J. Hudson (Eds.), Knowing and remembering in young children (pp. 166-196). New York, NY: Cambridge University Press.

Hume, D. (1748/2004). An enquiry concerning human understanding. New York, NY: Dover Publications.

Husserl, E. (1964). The phenomenology of internal time-consciousness. Bloomington, IN: Indiana University Press.

Ingvar, D. H. (1985). Memory of the future: An essay on the temporal orientation of conscious awareness. Human Neurobiology, 4, 127-136.

James, W. (1890). . Principles of psychology (Vol. 1) New York, NY: Henry Holt and Company.

Johnson, M. K., Hashtroudi, S., \& Lindsay, D. S. (1993). Source monitoring. Psychological Bulletin, 114, 3-28.

Kang, S. H. K., McDermott, K. B., \& Cohen, S. M. (2008). The mnemonic advantage of processing fitness-relevant information. Memory \& Cognition, 36, 1151-1156.

Kelly, E. R. (1882). The alternative: A study of psychology. London, UK: Macmillan.

Klee, R. (1997). Introduction to the philosophy of science: Cutting nature at its seams. New York, NY: Oxford University Press.

Klein, S. B. (2007). Phylogeny and evolution: Implications for understanding the nature of a memory system. In H. L. Roediger, Y. Dudai, \& S. Fitzgerald (Eds.) Science of memory: Concepts (pp. 377-381). New York, NY: Oxford.

Klein, S. B. (2010). The self: As a construct in psychology and neuropsychological evidence for its multiplicity. WIREs Cognitive Science, 1, 172-183.

Klein, S. B. (2012). A role for self-referential processing in tasks requiring participants to imagine survival on the savannah. Journal of experimental Psychology: Learning Memory \& Cognition, 38, 1234-1242.

Klein, S. B. (2013a). Making the case that episodic recollection is attributable to operations occurring at retrieval rather than to content stored in a dedicated subsystem of long-term memory. Frontiers in Behavioral Neuroscience, 7, 3. http://dx.doi.org/10.3389/fnbeh.2013.00003

Klein, S. B. (2013b). The complex act of projecting oneself into the future. WIRES Cognitive Sciences, 4, 63-79.

Klein, S. B. (in press). Evolution, memory, and the role of self-referent recall in planning for the future. In B. L. Schwartz, M. L. Howe, M. P. Toglia, \& H. Otgaar (Eds.), What is adaptive about adaptive memory? New York: Oxford University Press (in press).

Klein, S. B., \& Gangi, C. E. (2010). The multiplicity of self: Neuropsychological evidence and 'its implications for the self as a construct in psychological research. The Year in Cognitive Neuroscience 2010: Annals of the New York Academy of Sciences, 1191, 1-15. 
Klein, S. B., \& Nichols, S. (2012). Memory and the sense of personal identity. Mind, 121, 677-702.

Klein, S. B., Cosmides, L., Tooby, J., \& Chance, S. (2001). Priming exceptions: A test of the scope hypothesis in naturalistic trait judgments. Social Cognition, 19, $443-468$.

Klein, S. B., Cosmides, L., Tooby, J., \& Chance, S. (2002). Decisions and the evolution of memory: Multiple systems, multiple functions. Psychological Review, 109, 306-329.

Klein, S. B., Loftus, J., \& Kihlstrom, J. F. (2002). Memory and temporal experience: The effects of episodic memory loss on an amnesic patient's ability to remember the past and imagine the future. Social Cognition, 20, 353-379.

Klein, S. B., German, T. P., Cosmides, L., \& Gabriel, R. (2004). A theory of autobiographical memory: Necessary components and disorders resulting from their loss. Social Cognition, 22, 460-490.

Klein, S. B., Cosmides, L., Gangi, C. E., Jackson, B., Tooby, J., \& Costabile, K. A. (2009). Evolution and episodic memory: An analysis and demonstration of a social function of episodic recollection. Social Cognition, 27, 283-319.

Klein, S. B., Lax, M. L., \& Gangi, C. E. (2010). A call for an inclusive approach to the social cognitive neurosciences. Social Cognition, 28, 747-755.

Klein, S. B., Robertson, T. E., \& Delton, A. W. (2010). Facing the future: Memory as an evolved system for planning future acts. Memory \& Cognition, 38, 13-22.

Klein, S. B., Roberson, T. E., \& Delton, A. W. (2011). The future-orientation of memory: Planning as a key component mediating the high levels of recall found with survival processing. Memory, 19, 121-139.

Koriat, A., \& Goldsmith, M. (1996). Memory metaphors and the laboratory/real-life controversy: Correspondence versus storehouse views of memory. Behavioral and Brain Sciences, 19, 167-188.

Kroneisen, M., \& Erdfelder, E. (2011). On the plasticity of the survival processing effect. Journal of Experimental Psychology: Learning, Memory, E Cognition, 37. 1553-1562.

Kvale, S. (1974). The temporality of memory. Journal of Phenomenological Psychology, $5,7-31$

Kwan, D., Carson, N., Addis, D. R., \& Rosenbaum, R. S. (2010). Deficits in past remembering extend to the future in a case of developmental amnesia. Neurospychologia, 48, 3179-3186.

Lashley, K. (1950). In search of the engram. Society of Experimental Biology, Symposium, 4, 454-482.

Leary, M. R., \& Tangney, J. P. (2012). Handbook of self and identity (2nd ed.). New York, NY: The Guilford Press.

Llinas, R. R. (2001). I of the vortex: From neuron to self. Cambridge, MA: MIT Press.

Locke, D. (1971). Memory. London, UK: The Macmillan Press, Ltd.

Loizou, A. (1986). The reality of time. Aldershot, UK: Gower Publishing Co.

Markowitsch, H. J., \& Staniliou, A. (2011). Memory, autonoetic consciousness, and the self. Consciousness and Cognition, 20, 16-39.

Marshall, C. R. (2006). Explaining the Cambrian explosion of animals. Annual Review of Earth and Planetary Sciences, 34, 355-384.

Martin, C. B., \& Deutscher, M. (1966). Remembering. Philosophical Review, 75, 161-196.

Mayr, E. (2001). What evolution is. New York, NY: Basic Books.

McCarthy, R. A., \& Warrington, E. K. (1992). Actors but not scripts: The dissociation of people and events in retrograde amnesia. Neuropsychologia, 30, 633644.

McLure, R. (2005). The philosophy of time. New York, NY: Routledge.

McTaggart, J. M. E. (1908). The unreality of time. Mind, 68, 457-484.

Michaelian, K. (2010). Is memory a natural kind? Memory Studies, 4, 170-189.

Moulin, C. J. A., Souchay, C., \& Morris, R. G. (Eds.). (2013). Special issue: The cognitive neuropsychology of recollection. Cortex, 49, 1445-1609.

Mulcahy, N. J., \& Call, J. (2006). Apes save tools for future use. Science, 312, 10381040.

Mullally, S. L., \& Maguire, E. A. (2013). Memory, imagination, and predicting the future: A common brain mechanism? The Neurosientist (in press).

Mullally, S. L., Hassabis, D., \& Maguire, E. A. (2012). Scene construction in amnesia: An fMRI study. The Journal of Neuroscience, 32, 5646-5663.

Mullen, M. K., \& Yi, S. (1995). The cultural context of talk about the past: Implications for the development of autobiographical memory. Cognitive Development, 40, 276-297.

Nairne, J. S. (2005). The functionalist agenda in memory research. In A. F. Healy (Ed.), Experimental cognitive psychology and its applications: A Festschrift in honor of Lyle Bourne, Walter Kintsch and Thomas Landaur (pp. 115-126). Washington, DC: American Psychological Association.

Nairne, J. S. (2010). Adaptive memory: Evolutionary constraints on remembering. In B. H. Ross (Ed.), The psychology of learning and motivation (Vol. 53) (pp. 1-32). London, UK: Academic Press.

Nairne, J. S., \& Pandeirada, J. N. S. (2008). Adaptive memory: Remembering with a stone-age brain. Current Directions on Psychological Science, 17, 239-243.

Nairne, J. S., Pandeirada, J. N. S., Gregory, K. J., \& Van Arsdall, J. E. (2009). Adaptive memory: Fitness relevance and the hunter-gatherer mind. Psychological Science, 20, $740-746$

Neath, I. (1998). Human memory: An introduction to research, data, and theory. Pacific Grove, CA: Brooks/Cole Publishing Company.

Nelson, K. (1989). Narratives from the crib. Cambridge, MA: Harvard University Press.

Nelson, K. (1993). The psychological and social origins of autobiographical memory. Psychological Science, 1, 1-8.

Nelson, K. (1996). Language in cognitive development: The emergence of the mediated mind. New York, NY: Cambridge University Press.

Norman, D. A. (1970). Models of human memory. San Francisco, CA: Academic Press.
Otgaar, H., Smeets, T., \& van Bergen, S. (2010). Picturing survival memories: Enhanced memory after fitness-relevant processing occurs for both verbal and visual stimuli. Memory \& Cognition, 38, 23-28.

Parker, J. A., Crawford, M., \& Harris, P. (2006). Time and memory. Boston, MA: Brill

Pause, B. M. Zlomuzica, A., Kinugawa, K., Mariani, J., Pietrowsky, R., \& Dere, E. (2013). Perspectives on episodic-like and episodic memory. Frontiers in Behavioral Neuroscience, 7, 3. http://dx.doi.org/10.3389/fnbeh.2013.00033

Prebble, S., Addis, D. R., \& Tippett, L. J. (2000). Autobiographical Memory and Sense of Self. Psychological Bulletin, in press.

Puff, C. R. (1982). Handbook of research methods in human memory and cognition. New York, NY: Academic Press.

Race, E., Keane, M. N., \& Verfaellie, M. (2011). Medial temporal lobe damage causes deficits in episodic memory and episodic future thinking not attributable to deficits in narrative construction. Journal of Neuroscience, 31, 10262-10269.

Reid, T. (1813/1969). Essays on the intellectual powers of man. Cambridge, MA: MIT Press.

Roberts, W. A. (2002). Are animals stuck in time? Psychological Bulletin, 128, 473-489. Roberts, W. A. (2012). Evidence for future cognition in animals. Learning and motivation, 43, 169-180.

Roediger, H. L. (1996). Memory illusions. Journal of Memory and Language, 35, 76-100.

Roediger, H. L. (1980). Memory metaphors in cognitive psychology. Memory \& Cognition, 8, 231-246.

Russell, B. (1921). The analysis of mind. London, UK: George Allen \& Unwin.

Saint Augustine. (1997). The confessions. Hyde park, NY: New City Press (Translated by M. Boulding).

Schacter, D. L. (1995). Memory distortion: How minds, brains, and societies reconstruct the past. Cambridge, MA: Harvard University Press.

Schacter, D. L. (2012). Adaptive constructive processes and the future of memory. American Psychologist, 67, 603-613.

Schacter, D. L., Addis, D. R., Hassabis, D., Martin, V. C., Spreng, R. N., \& Szpunar, K. K. (2012). The future of memory: Remembering, imagining, and the brain. Neuron, 76, 677-694

Schacter, D. L., \& Tulving, E. (Eds.). (1994). Memory systems. Cambridge, MA: MIT Press.

Schacter, D. L., Guerin, S. A., \& St. Jacques, P. L. (2011). Memory distortion: An adaptive perspective. Trends in Cognitive Sciences, 15, 467-474.

Schneider, D. J. (2004). The psychology of stereotyping. New York, NY: The Guildford Press.

Sherry, D. F., \& Schacter, D. L. (1987). The evolution of multiple memory systems. Psychological Review, 94, 439-454.

Snodgrass, J. G., \& Thompson, R. L. (1997). . The self across psychology: Self-recognition, self-awareness, and the self-concept (Vol. 818) New York, NY: Annals of the New York Academy of Sciences.

Soderstorm, N. C., \& McCabe, D. P. (2011). Are survival processing memory advantages based on ancestral priorities? Psychonomic Bulletin \& Review, 18, 564-569.

Sorabji, R. (1972). Aristotle on memory. Providence, RI: Brown University Press.

Squire, L. R. (1987). Memory and brain. New York: Oxford University Press.

Squire, L. R. (2004). Memory systems of the brain: A brief history and current perspective. Neurobiology of Learning and Memory, 82, 171-177.

Suddendorf, T. (2010). Episodic memory versus episodic foresight: Similarities and differences. WIREs Cognitive Science, 1, 99-107.

Suddendorf, T., Addis, D. R., \& Corbaillis, M. C. (2009). Mental time travel and the shaping of the mind. Philosophical Transactions of the Royal Society B, 364, 1317-1324.

Suddendorf, T., \& Corballis, M. C. (1997). Mental time travel and the evolution of the human mind. Genetic, Social, and General Psychology Monographs, 123, 133-167.

Suddendorf, T., \& Corballis, M. C. (2007). The evolution of foresight: What is mental time travel, and is it unique to humans? Behavioral and Brain Sciences, 30, 299-313.

Sutton, J. (1998). Philosophy and Memory Traces: Descartes to connectionism. Cambridge, UK: Cambridge University Press.

Szpunar, K. H. (2010). Episodic future thought: An emerging concept. Perspectives on Psychological Science, 5, 142-162.

Szpunar, K. K., Watson, J. M., \& McDermott, K. B. (2007). Neural substrates of envisioning the future. Proceedings of the National Academy of Sciences of the United States of America, 104, 642-647.

Tulving, E. (1972). Episodic and semantic memory. In E. Tulving, \& W. Donaldson (Eds.), Organization of memory (pp. 381-403). New York, NY: Academic Press.

Tulving, E. (1983). Elements of episodic memory. New York, NY: Oxford University Press.

Tulving, E. (1985). Memory and consciousness. Canadian Psychology/Psychologie Canadienne, 26, 1-12

Tulving, E. (1993). What is episodic memory? Current Directions in Psychological Science, 2, 67-70.

Tulving, E. (2002). Episodic memory: From mind to brain. Annual Review of Psychology, 53, 1-25.

Tulving, E. (2005). Episodic memory and autonoesis: Uniquely human? In H. S. Terrace, \& J. Metcalfe (Eds.), The missing link in cognition: Origins of self-reflective consciousness (pp. 3-56). Oxford, UK: Oxford University Press.

Tulving, E., \& Craik, F. I. M. (2000). The Oxford handbook of memory. Oxford, UK: Oxford University Press.

Tulving, E., \& Lepage, M. (2000). Where in the brain is the awareness of one's past. In D. L. Schacter, \& E. Scarry (Eds.), Memory, brain, and belief (pp. 208-228). Cambridge, MA: Harvard University Press.

Vallentine, J. W. (2002). Prelude to the Cambrian explosion. Annual Review of Earth and Planetary Sciences, 32, 285-306. 
Vallentine, J. W. (2004). On the origin of phyla. Chicago, IL: University of Chicago Press.

Von Feinaigle, M. G. (1813). The new art of memory, founded upon the principles taught by $M$ Gregor von Feinaigle: and applied to chronology, history, geography, languages, systematic tables, poetry, prose, and arithmetic (2nd ed.). London, UK: Sherwood, Neely and Jones.

Warnock, M. (1987). Memory. Boston, MA: Faber and Faber.

Weinstein, Y., Bugg, J. M., \& Roediger, H. L. (2008). Can the survival recall advantage be explained by basic memory processes? Memory E' Cognition, 36, 913-919.
Wheeler, M. A., Stuss, D. T., \& Tulving, E. (1997). Toward a theory of episodic memory: The frontal lobes and autonoetic consciousness. Psychological Bulletin, 121 331-354.

Williams, G. C. (1966). Adaptation and natural selection: A critique of some current evolutionary thought. Princeton, NJ: Princeton University Press,

Willingham, D. B., \& Goedert, K. (2001). The role of taxonomies in the study of human memory. Cognitive, Affective, \&' Behavioral Neuroscience, 1, 250-265.

Yates, F. A. (1966). The art of memory. Chicago, IL: The University of Chicago Press. Young, J. Z. (1976). The evolution of memory. Burlington, SC: Carolina Biological Supply Company, Scientific Publication Division. 